Palaeontology

\section{Relationships between reptiles}

\author{
from T.S. Kemp
}

Palaeontology has come under increasing criticism because of the alleged lack of objectivity and rigour. The emergence of cladistic analysis - a taxonomic theory that aims to provide an objective basic for recognizing relationships between organisms - has been an important development but one that is not yet accepted by all palaeontologists. Moreover, evolutionary scenarios about how and why particular transitions occurred are frequently dismissed as no more than speculative story-telling of no scientific value. It is interesting to look at two important recent papers on fossil reptiles (Carroll, R.L. and Gaskill, P. Phil. Trans. R. Soc. B309, 343; Chatterjee, S. ibid, 395) in the light of such attacks. Both are written in the traditional mould of palaeontology, with detailed anatomical description, discussion of evolutionary relationships that include recognition of ancestry but not formal cladistic analysis, and interpretation of functional anatomy and evolution.

Carroll and Gaskill have described a species of a marine reptile from the Middle Triassic of Italy, a member of the Nothosauria. Nothosaurs are generally smaller, much more primitive and earlier than the more familiar marine reptile group of the Mesozoic, the plesiosaurs, and for many years it has been assumed that nothosaurs are the ancestors or at least the closest known relatives of the plesiosaurs. One of the authors' main purposes in this paper is to use the structure of nothosaurs to elucidate the origin of the highly specialized locomotory mechanism of plesiosaurs.

The nothosaurs have a long trunk, limbs that are reduced in size but are still basically recognizable as tetrapod and a powerfully built tail. By analogy with modern aquatic reptiles such as crocodiles and certain iguanid lizards, the authors suggest that the basic swimming action consisted of lateral undulations of the tail and trunk, and the limbs were only for steering. The shoulder girdle of nothosaurs is surprisingly robust, however, so they propose that the animal could also move on land, by dragging its body forwards using the forelimbs - analogous to the terrestrial locomotion of sea lions.

Plesiosaur limbs, both fore and hind, are much larger, although they are more modified from the basic reptilian type. The trunk is shorter and apparently fairly rigid, and the tail is weak. Carroll and Gaskill's evolutionary scenario is, therefore, that the limbs and girdles of a nothosaur-like animal continued to strengthen and enlarge until they could produce locomotory thrust in water, and the need for lateral undulation of the trunk

\section{and tail was lost}

Possible, perhaps plausible, as the hypothesis is, we must ask whether it has real scientific value. Certainly this functional analysis of locomotion in the nothosaurs, based on a combination of analogy with living reptiles and interpretation of the design features, is potentially testable: demonstration of features mechanically incompatible with the hypothesis would effectively refute it.

More dubious is the hypothesis that nothosaurs represent a stage in the evolution of the plesiosaurs. Nothosaurs and plesiosaurs possess a series of apparently derived characters in common, indicating a sister-group relationship, a conclusion reinforced in this account. It cannot be assumed that where nothosaurs differ from plesiosaurs, the nothosaur characters show the ancestral condition. This must be positively demonstrated by comparison with an unrelated outgroup, presumably of other reptiles. It emerges from
Carroll and Gaskill's account that in the postcranial skeleton, the only obviously shared derived character is the general arrangement of the shoulder girdle, and even here the similarity is not very close. Therefore, an equally plausible scenario is that the reduced size of the limbs, long trunk and powerful tail of nothosaurs are independent specializations - the common ancestor of this group and plesiosaurs would have been much less modified from normal reptiles than supposed. Indeed, a third possibility is that nothosaur locomotion evolved from a primitive version of plesiosaur locomotion. Because Carroll and Gaskill have selected one story from several equally unsupported possibilities, their choice may be accused of a lack of objectivity.

This criticism may be too restrictive to be fair. Their particular hypothesis does imply the potential existence, as fossils, of certain specifiable anatomical forms. Although a hypothesis cannot be refuted directly because of the failure to find particular kinds of fossils, the relative amount of evidential support for it may be reduced by the discovery of fossils consistent with an alternative hypothesis. For this reason scenarios of this kind can be regarded as properly scientific, although with the reservation that support for them is fairly weak. It is all too easy to demand that the level of evidence supporting a hypothesis be raised before it can be accepted as scientifically valid. Palaeontology will always have to be satisfied with relatively weakly corroborated hypotheses of evolutionary processes, but this is better than eschewing such hypotheses altogether, as those that criticize scenarios seem to wish.

Chatterjee's contribution concerns some very well preserved specimens of an archosaurian reptile from the Late Triassic of Texas. Postosuchus is a large rauisuchian thecodont, some 4 metres long including the tail and standing about 2 metres high. The rauisuchians have only relatively recently been understood as a group of large carnivores that pre-dated the carnivorous dinosaurs. Indeed, much of the confusion arose from the misinterpretation of fragments of rauisuchian skeletons as those of true dinosaurs (see Benton, M. Nature 310, 101; 1984). It is now clear that the group thrived during the Triassic but was replaced by the carnivorous dinosaurs at the end of that period. Postosuchus belongs in the family Popposauridae, which contains forms that seem to have paralleled the dinosurs in certain respects, such as becoming facultatively bipedal.

Chatterjee's most controversial conclusion comes from his comparison between Postosuchus and the tyrannosaurian

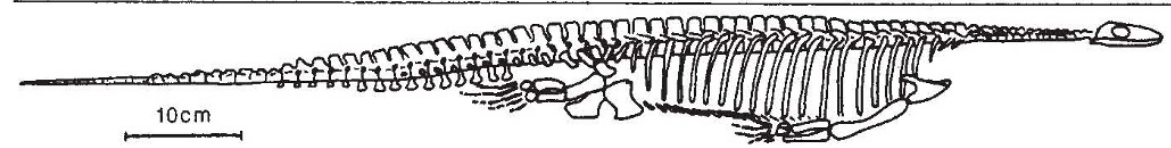

Reconstructed skeleton of the nothosaur Pachypleurosaurus edwardsi.

dinosaurs of the Cretaceous. He finds a number of similarities which lead him to suggest a close relationship between the two groups, to the exclusion of all other dinosaurs. This implies that tyrannosaurs evolved independently of other dinosaurs and flatly contradicts the growing belief that dinosaurs are, after all, a monophyletic group within the archosaurs (Benton, M. Nature 312, 599; 1984). Chatterjee lists 28 'diagnostic' characters shared between Postosuchus and Tyrannosaurus. Because he has not approached the problem cladistically, however, it is not clear which of these points of similarity are probably primitive (plesiomorphic), which can be suspected of convergence, and which are good candidates for synapomorphy and can be regarded as proper evidence for a cladistic relationship. It is therefore impossible to evaluate the quantity or quality of the evidence in support of his new hypothesis of relationships, short of re-doing the whole taxonomic exercise.

Nothing could illustrate more clearly the need for rigorous cladistic methods of analysis and expression than a paper such as this. The time has surely come when it is the application of non-cladist methodology that requires explicit justification, making cladism the normal procedure.

T.S. Kemp is Curator of the University Museum, Parks Road, Oxford OXI 3PW, UK. 